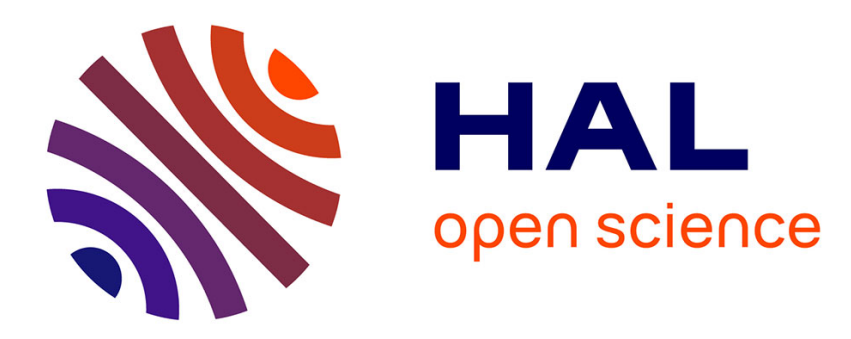

\title{
Conversations about Science across Activities in Mexican-Descent Families
}

Justin Dillon

\section{To cite this version:}

Justin Dillon. Conversations about Science across Activities in Mexican-Descent Families. International Journal of Science Education, 2007, 29 (12), pp.1447-1466. 10.1080/09500690701494100 . hal-00513354

\section{HAL Id: hal-00513354 \\ https://hal.science/hal-00513354}

Submitted on 1 Sep 2010

HAL is a multi-disciplinary open access archive for the deposit and dissemination of scientific research documents, whether they are published or not. The documents may come from teaching and research institutions in France or abroad, or from public or private research centers.
L'archive ouverte pluridisciplinaire HAL, est destinée au dépôt et à la diffusion de documents scientifiques de niveau recherche, publiés ou non, émanant des établissements d'enseignement et de recherche français ou étrangers, des laboratoires publics ou privés. 


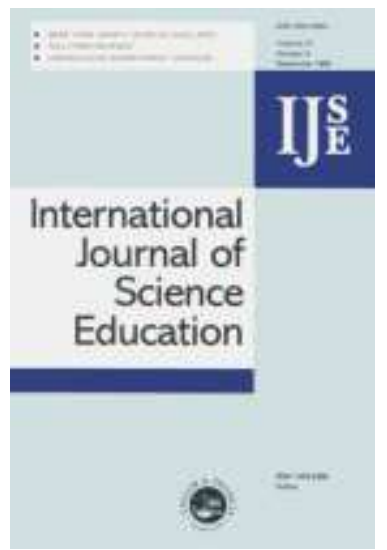

Conversations about Science across Activities in MexicanDescent Families

\begin{tabular}{|r|l|}
\hline Journal: & International Journal of Science Education \\
\hline Manuscript ID: & TSED-2007-0180 \\
\hline Manuscript Type: & Special Issue Research Paper \\
\hline Keywords: & informal education \\
\hline Keywords (user): & \\
\hline \multicolumn{2}{|l}{} \\
\hline
\end{tabular}

\section{s ScholarONE" \\ Manuscript Central}


Running head: CONVERSATIONS ABOUT SCIENCE

Conversations about Science across Activities in Mexican-Descent Families

\begin{abstract}
Parent-child ‘everyday' conversations have been suggested as a source of children's early science learning (Ash, 2003; Callanan \& Jipson, 2001). If such conversations are important then it would be pertinent to know whether children from different family backgrounds have different experiences talking about science in informal settings. We focus on the relation between parents' schooling and both their explanatory talk in science-related activities, and the styles of interaction they use with their children. Families from different schooling backgrounds within one underrepresented group in science education - Mexican-descent families - were included in this study. Forty families were observed in two science-related activities. In the sink-or-float task, families were asked to predict which of a variety of objects would sink and which would float, and then to test their predictions in a tub of water. The second activity was an open-ended visit to a local children's museum. Results showed similar patterns in scientific talk on the sinkor-float task across the two groups. However, interaction style varied with schooling across the two activities; parents with higher schooling were more directive than parents with basic schooling. Interaction style was also found to vary with task structure, with more open-ended tasks affording more collaborative interactions. Such research into parent-child conversations in science-related activities can help begin to guide us in bridging children's learning environments - home, school, and museum - and potentially fostering children's science learning, particularly in those groups underrepresented in the sciences.
\end{abstract}


Conversations about Science across Activities in Mexican-Descent Families

\author{
Deborah R. Siegel \\ University of California, Santa Cruz \\ Jennifer Esterly \\ California State University, Stanislaus \\ Maureen A. Callanan \\ University of California, Santa Cruz \\ Ramser Wright \\ University of California, Santa Cruz
}

\begin{abstract}
Deborah R. Siegel, Department of Psychology, University of California; Maureen A. Callanan, Department of Psychology, University of California; Jennifer Esterly, Department of Psychology and Child Development California State University, Stanislaus; Ramser Wright, Department of Psychology, University of California.

Correspondence concerning this article should be addressed to Deborah R. Siegel, Department of Psychology, Social Sciences 2, University of California Santa Cruz, Santa Cruz, CA 95064, email: dsiegel@ucsc.edu, office phone: 831-459-4876.
\end{abstract}


Conversations about Science across Activities in Mexican-Descent Families

Children's earliest ideas about the natural and technological world begin to be shaped by their observations of and interactions with the people around them (Goodnow, 1990; Rogoff, 2003). Conversations with parents and other family members give young children hints and guidance about how adults in their cultural community think about the biological, physical, and technological world (Ash, 2003; Callanan \& Oakes, 1992; Callanan \& Jipson, 2001, Crowley \& Galco, 2001). Research supporting this view of the social nature of early science learning shows that, in subtle ways, parents' language use provides children with potentially useful information about how they mentally carve up domains (e.g., into living and non-living), and about what types of words are conventionally used to describe what types of events (Callanan \& Jipson, 2001). This sociocultural view contrasts with the more traditional view of young children as developing understanding of different domains of knowledge in a somewhat maturational way.

If parent-child conversations are as important as they are argued to be by sociocultural researchers, then it would be crucial to know whether children from different family backgrounds have different experiences talking about science concepts in informal settings. Relatively little research has investigated such differences in science talk, but there is a great deal of evidence that parents with different levels of formal schooling interact with their children differently. While some researchers have found directive and controlling behaviours to be more characteristic of parents with more basic levels of schooling (Laosa, 1978, 1980) others have observed these behaviours in parents with higher levels of schooling (Rogoff, Mistry, Goncu, \& Mosier, 1993; Rogoff \& Toma, 1997).

As we examine interactions in families from diverse backgrounds, one group that is important to include is Latino families living in the United States. This population was selected 
since Latinos are underrepresented in the sciences as compared to other groups (Rosebery \& Warren, 1999). United States Census data from 2000 showed that while the Latino population made up about $10.7 \%$ of the total workforce, this group comprised only $3.0 \%$ of the STEM (science, technology, engineering and mathematics) workforce (National Science Foundation, 1999). Investigation into this area has important applications, as Latino children are a fast growing group in U.S. schools, yet a group that is underrepresented in higher education and in science fields (Chapa \& Valencia, 1993). Previous research also suggests that parental schooling is linked in important ways to patterns of parent-child interaction (Rogoff, 2003). Working with the Mexican immigrant population in California allows us to compare parents from similar heritage but with varying experience with schooling; the Mexican-descent communities in Central California include both parents with basic schooling and those with higher levels of schooling.

There is not a great deal of research on science talk in Latino or Mexican-descent ${ }^{1}$ families, but Tenenbaum \& Callanan (2006) found that, in a museum setting, different kinds of explanations about science were used by Mexican-descent mothers with higher schooling (those who had completed at least 12 years of schooling) than by those with basic schooling (those who had completed fewer than 12 years of formal schooling). On a set of museum-like tasks at home, however, there were fewer differences between the two groups. In particular, parents with higher schooling were more likely to talk about making predictions and testing them out than were parents with basic schooling. However, in both the museum and the home setting, parents with basic schooling were just as likely to use causal explanations when talking about science content. 
While this analysis of explanations, broadly defined, provides a first step in investigating family science talk, it is crucial to delve more deeply into specific scientific content if we are to be able to draw conclusions about how children are learning about science in everyday interactions. We chose specific phenomena to be explained by focusing on the topic of buoyancy. Esterly (2001) has explored understanding of buoyancy in both children and adults, finding that full explanations of density are rarely given. In this work we explore the types of predictions and explanations for sinking and floating events that parents from different schooling backgrounds construct with their children.

While the theme of exploring family science talk emerges in cognitive developmental research, in science education research, and in sociocultural research, the three literatures are quite disconnected. In order to link the research on family science talk more closely with the research on cultural variation in family interaction, then, these studies also focus on variations in interactional style. At the same time that we focus on one specific area of scientific content, then, we also ask whether parents' schooling is related to variation in the style of interaction they use when discussing science with their children. In previous research there are suggestions that parents' schooling is related to their style of interaction with their children, however the findings are inconsistent. Some research suggests that parents with little formal schooling are more directive with their children (Laosa, 1978, 1980), while other studies find that parents with more schooling tend to be more directive and less collaborative (Rogoff \& Toma, 1997). These discrepancies may relate to variations in the tasks used; we explore potential links between parents' schooling and their interaction style across several different science-related activities.

In Study 1, we focus on family interactions while engaged in one particular area of science content: parent-child conversations about buoyancy, i.e., about what types of objects 
sink and float. Coding both the content of what families discuss as well as the style of interaction, we ask (1) whether parents with different schooling backgrounds discuss the scientific notion of density in different ways, and (2) whether parents with basic schooling and high schooling vary in their use of directive, collaborative, and instructional guidance strategies while engaging in science-related conversations with their children.

We also focus on how the structure of a task influences family interactions, by looking at two different phases of the buoyancy task (testing and prediction), and comparing family interactions in that task with their conversations in a more open-ended visit to a set of sciencerelated exhibits at a children's museum, in Study 2. In both studies, we also ask exploratory questions about whether the family conversations vary, in content or interactional style, depending on the age and/or gender of the children.

Study 1: Sink-or-Float Task

Method

\section{Participants}

Forty Mexican-descent families were recruited in the central coast region of California from community organizations that serve Latino families, from schools and apartment complexes in Latino neighbourhoods and by references of families who had participated in our previous studies. These same families took part in both the home and museum tasks. There were eight groups categorized by parental schooling level (high or basic), children's gender and children's age. The higher schooling group $(n=20)$ consisted of mothers with twelve to sixteen years of schooling $(M=13.32)$ and most were schooled in the U.S. Two of the parents were Spanishspeaking, one was English-speaking, and 17 were bilingual. The basic schooling group $(n=20)$ consisted of mothers with three to 11 years of schooling $(M=7.65)$ and most were schooled in 
Mexico. Seventeen of these parents were Spanish-speaking and three were bilingual. Children in the younger group were between $3 ; 1$ and 5;1 ( $M=52.8$ months) and children in the older group ranged from 5;4 to 9 years $(M=86.10$ months). There were equal numbers of boys and girls in each group.

Materials

Materials in this task included two plastic baskets used for sorting the objects. There was also a plastic container of water used by the families to test their predictions after sorting. The 18 objects used in the task included a bracelet, a crayon, a die, a plastic fish, a foam filled bottle, a plastic french fry, a toy frog castanet, a bottle filled with water, two toys that grow in water, a hippo-shaped cookie cutter, a kaleidoscope, a keychain, a marble filled bottle, a toy rabbit, a toy seal, a whiffle ball, and a yo-yo.

Procedure

The data for both studies were collected as part of a larger research project investigating parental use of causal explanations (Tenenbaum, Callanan, Alba-Speyer, \& Sandoval, 2002). The first study utilized data from videotaped interactions of parents and their children during a semistructured hands-on science task. To collect the data, experimenters visited participating families in their homes. Experimenters presented the task to the families as a water game. To maximize their comfort level, families were allowed to choose the location in their home where they completed the activity. In addition, all members of the family who were present were invited to participate (parents, siblings, grandparents, aunts, etc.). ${ }^{2}$ The following instructions were given to the families either in Spanish or English depending upon the family's preference:

Now we are going to ask you to play a game. We have this pile that has many different things. We also have two baskets and a big container filled with water. 
We are asking you and your child to put the things you think are going to sink into the blue basket and the things you think are going to float into the green basket. An important part of the game is to come up with reasons why you and your child think some things will float and some things will sink. After you have put everything into the two empty buckets and discussed the reasons, you can test your ideas using the bucket filled with water. We will wait outside for you. Please come get us when you feel that you have finished the activity.

Family members were told they could speak to one another in Spanish or English, whatever they were most comfortable with speaking. The camera was set up and the experimenters left the family alone for 10-15 minutes.

\section{Parents' Explanations Coding}

Videotapes were transcribed, translated, checked, and coded. Coding was completed by two different teams of research assistants; one member of each two person team was fluent in both Spanish and English. Both videotapes and transcripts were used for coding. Teams of coders, rather than individual coders, were utilized to help ensure reliability.

Parents' explanations for why items would sink or float were coded based on their interactions with the target child during both the prediction and testing phases of the activity. Explanations were coded in one of several specific categories (based on Esterly, 2001) which were grouped into four summary categories:

Density Explanations: Explanations describing the notion of density, including the link between weight and relative size (i.e. the notion that an object is heavy for its size). Density-Relevant Explanations: While not articulating the complete principle of density, explanations could refer to properties that are relevant to the notion of density: 
Material kinds (e.g. wood),

Weight (e.g. heavy)

Size (e.g. little)

Insides (e.g. hollow, full)

Relates to water (e.g. water part sinks \& air part floats)

Other Property Explanations: These include properties that are not relevant to density.

Texture (e.g. smooth, soft)

Shape (e.g. square)

Other properties (e.g. cold, squeaky)

Function/identity ( e.g. it cuts things, it's a key)

\section{No Information:}

Because

I don't know

Reliability was calculated across the two teams for $20 \%$ of the families. Inter-rater reliability was acceptably high, Cohen's kappas ranged from .73 to .94 , which is considered very good to excellent, Bakeman \& Gottman, 1997).

\section{Parents' Interaction Style Coding}

Parents' interaction style was coded based on their interactions with the target child. Sessions were divided into one-minute segments. A Spanish bilingual coder observed the taped sessions and coded each segment for interaction style. Interaction style was classified into three main categories based on verbal and nonverbal cues. This code was considered a global view of the interaction style of the parent where tone and nonverbal communication were very important to take into consideration and can mean the difference between two categories. 
Directive: The parent behaves as an expert who is teaching information to the child. Parent talk and behaviour focuses on transmitting knowledge to the child. There are many directives and lesson-like talk. (See Table 1 for examples of all of the categories).

Collaborative: The parent and child demonstrate an intention to work with each other in a joint manner. There is a great deal of turn-taking so neither parent nor child dominates the conversation. (See Table 1).

Instructional Guidance: The parent and child work together but at times the parent acts as an expert and guides the child through a process of scientific inquiry and discovery. (See Table 1).

Other: An 'Other' category was created to capture instances that do not fit into the other categories.

The experimenter trained two bilingual Spanish speaking researcher assistants. Coding 20\% of the total set of families yielded a percent agreement of $68 \%$ and Cohen's kappa of .61, which is considered 'good' (Bakeman \& Gottman, 1997). Discrepancies in coding were discussed and agreed upon. Toward the end of coding, the experimenter and one of the coders conducted a final reliability check on a subset of the English-speaking families. Cohen's kappa for this reliability was .91.

\author{
Results \\ Parents' Explanations about Sinking and Floating \\ We explored whether parents' explanations varied by their schooling experience or their \\ children's age or gender in a mixed analysis of variance: 2 (Age of child: younger, older) x 2 \\ (Gender of child) x 2 (Parents' schooling: Basic or Higher Schooling) x 2 (Phase of task: \\ Prediction or Testing) x 4 (Explanation Type: Density, Density-Relevant, Other property, No
}


information). Age, gender, and schooling were between subject factors; phase of task and explanation type were repeated measures. The only significant finding was a main effect for explanation type, $F(3,32)=56.28, p<.001$. Interestingly, then, parents with basic schooling and high schooling did not differ in the ways that they talked with their children about density. While very few density explanations were given, all parents were more likely to give densityrelevant explanations than all other types of explanations, as confirmed by follow-up t-tests (density-relevant explanations more frequent than density explanations, $t(39)=7.65, p<.01$; more frequent than other properties, $t(39)=7.44, p<.01$; and more frequent than no information, $t(39)=7.56, p<.01)$. The mean number of explanations of different types are presented in Table 2. In separate $2 \times 2 \times 2$ analyses we also asked whether families varied by Schooling, Age of child, or Gender of child in the mean number of different types of explanations offered, or in the mean number of different types of density-relevant explanations offered. There were no significant main effects or interactions on these measures.

Looking at the data more closely, we examined the relative frequency of the different types of density-relevant properties that were discussed in a 2 (Parents' Schooling) x 2 (Children's Age) x 5 (Density-Relevant Explanation Type: Weight, Material kind, Size, Insides, Water-related) ANOVA. There was a significant effect for Explanation type, $\mathrm{F}(4,36)=16.63$, $\mathrm{p}$ $<.001$. Parents were most likely to provide their children with weight explanations $(M=5.55, S D$ $=6.02)$. The other two most commonly used explanations referred to material kinds $(M=2.28$, $S D=3.78)$ and insides $(M=2.15, S D=2.76)$. In addition, explanation type interacted with children's age, $\mathrm{F}(4,36)=3.63, \mathrm{p}<.008$, because parents of younger children provided twice as many weight explanations as parents of older children, $t(38)=2.08, p<.05$. Again, parents from the different schooling groups did not differ in the types of explanations they gave. 


\section{Parents' Interaction Style}

Controlling for Task Length. Families varied in the length of the overall task as well as the length of the prediction and testing portions of the task. Therefore, to control for this and for the number of one-minute segments, percentages of segments coded in each interaction style were calculated, both for the overall task and for the prediction and testing tasks separately. Since percentages are not independent from each other, separate analyses were conducted for each interaction type. Analyses of variance revealed no significant age group differences, so further analyses were conducted collapsing across age groups.

Interaction Style in Overall Task. The overall means and standard deviations of the different parental interaction styles are presented in Table 3. A series of one-way analyses of variance were conducted, one for each of the four coding categories, with Schooling level (Basic, Higher) and Child's gender as the between subjects variables. The basic schooling group had significantly more segments coded as 'Other', $F(1,32)=7.89, p<.01$ than did the higher schooling group. This was primarily due to the presence of other family members in the task. All members of the family were invited to participate in addition to the target child and parent. In some families another parent and siblings were involved and this was more often the case for the basic schooling families. Segments where the parent was not interacting with the target child either because the parent was interacting with siblings or spouse, or because the parent was not interacting at all, were coded as 'Other'. Since the main purpose of this study was to look at parent-target child interactions, this category was not included in the subsequent analyses. ${ }^{3}$

Parental Schooling and Interaction Style. A series of $2 \times 2 \times 2$ analyses of variance were conducted for each interaction style, not including 'Other', with Parents' schooling (Basic, Higher) and Gender as between groups variables and Task (Prediction, Testing) as the within 
group variable. ${ }^{4}$ These analyses revealed that parents did not differ significantly in their style of interaction as a function of their schooling experience. Parents in both groups used Directive behaviours the majority of the time with their children. In the basic schooling group parents were Directive in $58.22 \%$ of their interactions $(S D=27.91$, this was greater than expected by chance, $t(19)=5.32, p<.01)$. In the higher schooling group, parents were Directive in $70.38 \%$ of their interactions $(S D=32.50$, which was also greater than expected by chance, $t(19)=6.24, p<.01)$.

The consistency across parents' schooling backgrounds on this task is in contrast to the findings of Rogoff and Toma (1997) and Laosa (1978, 1980), who found that parental interaction style varied with parents' schooling. Further discussion of this discrepancy with earlier findings will be included in the discussion.

Task and Interaction Style. The $2 \times 2 \times 2 \times 2$ analysis on Directive behaviours resulted in a main effect of Task type, showing that parents used significantly more Directive behaviours in the prediction task than in the testing task, $F(1,30)=9.04, p<.01$. There was also a trend of more Collaborative behaviours in the testing task than in the prediction task, $F(1,30)=54.14, p$ $=.051$. No significant interaction was found between parental schooling level and task type for any of the interaction styles.

Gender Differences. There was a main effect of Gender for the Collaborative interaction style, $F(1,30)=4.576, p<.05$. Parents of boys displayed more collaborative behaviours than did parents of girls (boys $M=16.61, S D=24.59$, girls $M=6.27, S D=15.14$ ). There were no interactions between gender and schooling level.

\section{Discussion}

This study explored the ways parents talk to their children about science and how this relates to the amount of formal schooling experienced by the parent, as well as the type of task. 


\section{Parental Explanations about Sinking and Floating}

In a hands-on science task, American families of Mexican-descent engaged their children in rich explanatory conversations. This contrasts with previous claims that scientific causal explanation may be more characteristic of middle-class European-descent families (Rogoff et al. 1993). Moreover, regardless of parent schooling level, parents were likely to engage their children in buoyancy relevant explanatory conversations. These results do not support previous research which found conversational differences related to parent schooling level (e.g., Laosa, 1980). It is interesting to note that the parents in our study, which utilized a semi-structured buoyancy task administered at home, provided a percentage of density and density relevant explanations (93.58\%) similar to that of college students $(90.43 \%)$ tested with a structured buoyancy task administered in a lab setting (Esterly, 2001).

It is difficult to be certain about why parents from different schooling backgrounds were similar in their talk about the science content in this task. Perhaps it is because the topic of sinking and floating is one for which all adults have familiarity with the basic issues (such as weight and material). Because the task was conducted in participants' homes, it is also possible that these findings may support the suggestion that schooling effects on parents' explanatory conversations are not as powerful in the familiar context of the home (Eisenberg, 2002).

\section{Parents' Schooling and Interaction Style}

Results of this study did not support the findings of Rogoff and Toma (1997) or Laosa $(1978,1980)$ who found that interaction style varied with parental schooling level. Here, parents in both groups mainly used the Directive style of interaction. One reason the findings may differ from those of Rogoff and Toma is that different criteria were used in parental schooling groupings. Our study, similar to Laosa's, used 11th grade as the cut-off point between basic and 
higher schooling groups. On the other hand, Rogoff and Toma's schooling groups included 0-3rd grade in the basic schooling group and 6-9th grade in the higher schooling group. Most of the parents who participated in this study would have been grouped in the higher schooling group in their study. Perhaps parents with even a few years of school (for example six years) are socialized into the 'school-like' ways of interactions with their children and comparisons need to be made between parents with no formal schooling and those with many years of schooling. Some participants in this study did fit into Rogoff and Toma's groupings, however there were not enough families in each group to make sub-comparisons for our data.

Differences between our findings and Laosa's findings may relate more to the tasks used in both studies. While everyone is likely to have experience with objects in water, our sink/float task was purposely designed to be difficult so that opportunities for conversation would arise. In particular, we included objects about which it would be difficult to predict whether they would sink or float. Therefore, when working with their children, parents are not necessarily at an advantage in knowing the 'answers' to which will sink and which will float. Williamson and Silvern (1986) conducted a study where the parent and child worked on an open-ended teaching task where the expertise of the parent and child was equal. In this situation the parents were overwhelmingly directive. Laosa's tasks were not open-ended but closed-ended puzzle tasks where the parent is seen as the expert. Parental schooling background may be more associated with their interaction style when they are the 'expert' compared with their children.

\section{Task and Interaction Style}

In this study we found that parental interactions did change with the different parts of the task - prediction versus testing. Parents of both schooling groups were more directive in the prediction task and more collaborative in the testing task. This may have occurred because the 
prediction task involves mainly verbal communication where the parent and child discuss the properties of the objects and their predictions. This type of behaviour is captured best in the 'Directive' category. The testing task, on the other hand, is less verbal and more hands-on, which is better captured in the 'Collaborative' category. Also, once parents began to see that some of their predictions were incorrect, they may have been more open to alternative views about what was happening.

Another possible explanation for these differences may have been due to the nature of the overall task - the prediction task preceded the testing task. Order and the passage of time could have played a role in parents' change of interaction styles. Parents, regardless of the type of task, might begin by acting more directive, introducing the child to the task. As time passes the parent may withdraw control as the child becomes more comfortable with the task (Moreno, 1996).

\section{Gender and Interaction Style}

There was an unexpected effect of gender with parents of boys being more collaborative than parents of girls. It is difficult to ascertain whether it is the case that parents are treating boys differently than girls, or if they are responding to the children's behaviour, or if there is an interplay of both (Tenenbaum \& Leaper, 2003). Observing the videotaped interactions, one could see that when the task moved from the prediction to testing portion, boys often reacted by playing more and taking over the task. Anecdotally, girls did not do this as much. So, parents of boys might have been just letting their children lead in the testing task, which is more structured for play than the prediction task. Alternatively, differences may have been a result of how parents view boys' and girls' interest in science.

\section{Study 2: Museum Visit}


Overall, parents were quite directive in their interactional style in the sink-or-float task. In order to consider some of the reasons for this result, we compared parents from the two schooling groups in terms of their interaction style with their children in the more open-ended setting of a museum visit.

Participants

The same 40 Mexican-descent families from Study 1 participated in Study 2.

\section{Procedure}

Working in collaboration with the Children's Discovery Museum (San Jose, California), a bilingual researcher accompanied each family to the museum. Depending on the day, one to three families were driven individually to the museum. The Children's Discovery Museum is an interactive museum geared toward children ages 12 and under. Some examples of exhibits included a time-lapse photography exhibit with growing and dying plants, an x-ray examination board-light, a heart-beat drum that starts beating when hands are placed in the outlined hand map, a 'power-girl' electricity producing pendulum that works by moving back and forth, and an airplane that flies as ones rotates a crane.

Before the arrival at the museum, parents completed a demographic form. They were provided with a map in Spanish (because the signs at the museum were all in English at the time) and a brief tour of the museum. Researchers did not accompany families throughout the museum. Instead, they encouraged the families to roam freely by themselves and to visit at their leisure the exhibits that were being taped that day. Cameras were already set-up at various exhibits. Participating children wore stickers to identify them so that the camera operators would know that they could turn on the cameras when those children approached the exhibit. Families could stay as long as they liked at different exhibits. They were always taped at the time-lapse 
photography exhibit and at two other exhibits that varied. Typically, the latter included a zoetrope exhibit and a train exhibit. The researcher treated the family members to lunch and talked to them about their visit. When the family members were ready to leave, they were driven back home.

Parent Interaction Style Coding

The coding scheme for the museum exhibit was based on the one used in the home visit with minor changes to account for new types of interactions in the museum. In addition, as the museum visits were shorter and richer in action, coding was done in 20-second segments as opposed to one-minute segments.

Two additional categories were created to capture instances that did not fit into the three original interaction style categories. Only those segments in which the parent is interacting with the target child for at least part of the segment were coded. The two additional categories are elaborated below.

1) Directive

2) Collaborative

3) Instructional Guidance

4) Child-run. The child seems to be controlling or running the task.

5) Task Orientation. The parent and child are orienting themselves to the exhibit.

6) Other

The researcher randomly chose $20 \%$ of the total set of families used in the study. Five families were coded at the beginning of inter-coder reliability, coming to a Cohen's kappa of .72, which is considered 'very good' reliability (Bakeman \& Gottman, 1997). At the end of coding 
the data, inter-coder reliability was tested again to see how well reliability was maintained, resulting in a Cohen's kappa of .77.

\section{Results}

\section{Controlling for Task Length}

As in Study 1, families varied in the length of their overall interaction with the exhibits. Therefore, to control for this and the number of segments, percentages of segments coded in each interaction style were calculated. Also, as in Study 1, separate analyses were done for each interaction type.

\section{Parental Schooling Level and Interaction Style.}

The overall means and standard deviations of the different parental interaction styles are presented in Table 4. A series of one-way $2 \times 2 \times 2$ analyses of variance were conducted, one for each of the six coding categories with Schooling level (Basic, Higher), Child's gender and Child's age as between subjects variables. The higher schooling group had significantly more segments coded as Task Orientation than the basic schooling group $F(1,32)=7.325, p<.05$. In addition, there was a trend for parents with more schooling to display more Directive behaviours in the museum than parents with basic schooling, $F(1,32)=3.749, p=.062$. Parents in basic and higher schooling groups did not differ in the proportion in Collaborative or Instructional Guidance interactions.

\section{Gender and Age Differences.}

There was a main effect for Gender $(F(1,32)=4.28, \mathrm{p}<.05)$ in the Collaborative interaction style, with parents of girls $(M=25.44, S D=27.83)$ displaying more collaborative behaviours than parents of boys $(M=11.65, S D=15.03)$. Further, there was a main effect of Age $(F(1,32)=6.93, p<.05)$ with parents of older children $(M=27.32, S D=28.94)$ displaying 
more collaborative behaviours than parents of younger children $(M=9.77, S D=10.03)$. Comparing Interaction Style in Museum and Home Activities.

Separate $2 \times 2 \times 2 \times 2$ analyses of variance were conducted on those coding categories that appeared in both activities (Directive, Collaborative, and Instructional Guidance) with Parental schooling level, Child's gender and Child's age as the between subjects variables and Activity (Museum visit and Home sink-or-float activity) as the within subject variable.

In this analysis, we were interested in comparing parental interaction style across the two activities. Results show a main effect of Activity, with parents being more Directive in the home task than in the museum, $F(1,32)=16.02, p<.01$. A separate analysis on Collaborative interactions revealed an interaction of Activity and Gender, $\mathrm{F}(1,32)=8.25$, $\mathrm{p}<.01$, with parents of boys being equally Collaborative in both activities while parents of girls were more Collaborative in the museum than in the home task. (See Figure 1). In addition, to compare interaction styles across activities as well as the task-phases of the home task, separate $2 \times 2 \times 2$ x 3 analyses of variance were conducted on each interaction type, looking both across activities as well as within the home task, with Parents' schooling level, Child's gender and Child's age as the between subject variable and Task type (prediction phase, testing phase, and museum) as the within subject variable. Looking at Directive interactions, a main effect of Task type was found, $F(1,30)=24.99, \mathrm{p}<.01$. Follow-up analyses revealed that parents were most Directive in the prediction phase of the home task (prediction phase more than testing phase, $t(38)=3.15, p<$ .01 ; prediction phase more than museum, $t(38)=5.274, p<.01)$ and least Directive at the museum (museum less than testing phase, $t(38)=2.390, p<.05$ ).

Examining Collaborative interactions, there was a main effect of Task type, $F(1,30)=5.93, p<.05$. Interestingly, parental interaction style in the museum setting was more 
similar to the style demonstrated in the testing phase of the home task (a less structured activity), than to the prediction phase (a more structured activity), as shown by follow-up tests. Parents were least Collaborative in the prediction phase (prediction phase less than testing phase, $t(38)=$ $-2.04, p<.05$; prediction phase less than museum, $t(38)=-2.46, p<.05)$. There was also an interaction of Task and Gender, $F(1,30)=4.91, p<.05$. Follow-up independent-samples t-tests revealed that parents were most Collaborative with boys in the testing phase of the home task, $t(36)=-2.37 p<.05$. There was also a trend for parents of girls to be more Collaborative at the museum, $t(38)=1.95, p=.059$. Lastly, there was a trend involving Age, $F(1,30)=4.057, p=$ .053 , with parents being more Collaborative with older children than younger children.

Overall, across the two activities, we found significant effects of Schooling level and Age. In the analysis of Directive segments, parents with higher schooling displayed more 'Directive' behaviours than parents with basic schooling, $F(1,32)=4.98, p<.05$ and parents of younger children had more Directive segments than parents of older children, $F(1,32)=4.54, p<$ .05. In the analysis of Collaborative segments parents of older children had more 'Collaborative' segments than parents of younger children, $F(1,32)=6.52, p<.05$.

\section{Discussion}

This study examined how parents interacted with their children during science-related activities in a hands-on museum, and also compared these activities with the sink-or-float activity conducted in the home visit in Study 1. Of particular interest was how family interactions varied for families with different experiences of formal schooling.

Looking at parental interaction styles across these two settings, results showed that overall parents were more directive in the home science activity, a more closed-ended task, than at the museum, a more open-ended activity. The sink-or-float task was quite structured and thus 
it may have afforded a more directive or controlling type of interaction. Results of this analysis are consistent with the findings of Rogoff and Toma (1997) in the way that interaction style varied with parental schooling level. Across the two activities, but particularly in the museum setting, parents who had more experience with schooling were more directive with their children. In addition, as might be expected, parents tended to be more directive with younger children than with older children. Parents with more schooling may therefore be socialized in 'school-like' behaviours and this may in turn structure their interactions with their children. Parents' interaction style may also take into account the appropriate level of the children, therefore scaffolding the children in their learning.

Further, since differences within the sink-or-float task were found in Study 1, where parents were more directive in the prediction phase (a closed-ended activity) and more collaborative in the testing phase (a open-ended activity), we compared parents' interaction style at the museum (a open-ended activity) with their interaction styles in the two phases of the sinkor-float task. Task structure across these three activities did reveal interesting similarities and differences in interactional style. As might be expected, parents in both groups were most directive in the prediction phase of the sink-or-float task, a structured, closed-ended activity. Parents tended to be more collaborative in both the testing phase and at the museum. Thus, task structure and activity seems to have played a role in how parents interacted with their children.

Lastly, gender analyses revealed some unexpected findings. Whereas in Study 1 parents were more Collaborative with boys than with girls, (especially during the testing phase of the sink/float task), parents were more collaborative with girls than with boys at the museum.

General Discussion 
Children's science learning begins well before they step into the classroom. Starting from a young age, conversations with parents around everyday events often involve aspects of the biological, physical, and technological world (Ash, 2003; Callanan \& Oakes, 1992; Callanan \& Jipson, 2001; Crowley \& Galco, 2001). Examining such conversations proves fruitful in an attempt to better understand children's early science learning as well as the link between children's science learning inside and outside the classroom.

In these studies, we focused on a population underrepresented in the sciences, families of Mexican-descent, and looked at within group differences - focusing on variation among parents with different levels of schooling. Cross-cultural research has often been criticized for overlooking variability within cultural groups (Laosa, 1978). Such research on cultural differences in parent-child conversation may have failed to take into account other factors such as unequal schooling backgrounds (Laosa, 1980). Further, it has been suggested that formal schooling can have a pervasive socializing role in people's lives and can be observed in parentchild conversations about science (Laosa, 1978, 1980; Moreno, 1991; Renshaw, 1992). Thus, this study could give further insight into the variability within one cultural group by observing family interactions of parents within the Mexican-descent community with different experiences with schooling.

In the presented studies, we aimed to bridge research concerning family science talk from three often disparate areas - cognitive development, science education, and sociocultural research. In this vein, given research showing a relationship between family interactions and parental schooling, we observed parental interaction styles as well as the content of their talk(focusing on explanations about buoyancy) in a science-related activity involving objects that 
sink and float. Further, we asked if their interaction style would differ across activities by also observing families in a less structured setting at a children's science museum.

Interestingly, we found that regardless of parents' schooling, parents had similarly rich explanatory conversations with their children in the buoyancy task. Parents with basic schooling and those with higher schooling both focused on density-relevant features of objects, particularly weight, when discussing their predictions and their 'findings' about which objects floated and sank. Not surprisingly, both groups of parents discussed features of density without giving full scientific explanations of density; this is consistent with previous work on how college students explain sinking and floating events (Esterly, 2001).

Overall, we found that across the two activities, but especially in the museum setting, parents with higher schooling tended to be more directive with their children. Thus, parents' experience with formal schooling in our studies does seem to relate to their later interactions with their children in the ways reported by Rogoff and her colleagues (Rogoff, et al, 1993; Rogoff \& Toma, 1997). This is in contrast to the work of Laosa $(1978,1980)$ where parents from basic schooling backgrounds were likely to be more directive. Laosa's puzzle tasks may have encouraged different types of interaction styles from the two groups of families than did our science-oriented tasks (see also Moreno, 1996). The importance of the task context is apparent in the interesting variations we found across the different activity settings. In the buoyancy task, both groups of parents interacted with their children in a similar manner - being mostly directive. Looking at interactions in the museum, on the other hand, there was a trend for parents with higher schooling to be more directive than those with basic schooling. In a more open-ended setting, but where the focus was on science, parents with higher schooling continued to behave 
as they did in the structured task, perhaps using school-like strategies for discussing the exhibits with their children.

These findings provide insights and raise intriguing questions for educators in both formal and informal settings. We presented families with a scientific activity focused on a topic (sinking and floating) about which many adults have familiarity but do not have detailed explanatory scientific knowledge (Esterly, 2001). In this activity, we observed parents from very different schooling backgrounds giving children similar information about the features of objects that are relevant to the more scientific concepts (e.g. buoyancy, density) that they will later encounter in science classrooms. The similarity in the conversations across the two groups may be surprising to teachers and museum educators.

Our studies also raise many questions about the impact of different types of activities for family conversations. It is intriguing that family interaction styles changed even with fairly subtle differences in the task, such as the switch from the prediction phase to the testing phase of the sink-or-float activity. Many educators in both formal and informal settings suggest that more collaborative and/or inquiry-based activities are likely to lead children to more authentic joint learning experiences than are more directive interactions with adults (National Science Foundation, 1999; Rosebery \& Warren, 1999). The findings of our studies add some support to the idea that open-ended activities such as museum visits may encourage more collaborative discussions about science between adults and children. Though in the buoyancy task, parents were more directive in the prediction phase, providing children with relevant scientific explanations for their predictions, their interactions style changed in the testing phase where parents were quite often just as surprised as their children were with the results of their predictions. When parents are learning along with their children, they may also guide their 
children in subtle ways, using their own experience in the world and their understanding of vocabulary and explanations that are relevant to the activity.

It is our hope that these findings can also add to our understanding of diversity in family interaction, and that better understanding of families' interactional styles can perhaps help to bridge children's learning at home and in formal and informal learning environments. It is especially important to increase our awareness of styles of conversation and interaction for children from groups who are underrepresented in the sciences so that we can help to foster scientific literacy in all children. Contrary to the expectations of some educators, our results suggest that parents from a variety of schooling backgrounds may be providing their children with useful guidance in the understanding of science topics. 


\section{References}

Ash, D. (2003). Dialogic inquiry in life science conversations of family groups in museums. Journal of Research in Science Teaching, 40, 138-162.

Bakeman, R., \& Gottman, J. (1997). Observing interaction: An introduction to sequential analysis. New York: Cambridge University Press.

Callanan, M., \& Jipson, J. L. (2001). Explanatory conversations and young children's developing scientific literacy. In K. Crowley, C. D. Schunn, \& T. Okada (Eds.), Designing for science: Implications from everyday, classroom, and professional settings (pp. 21-49). Mahwah, NJ: Erlbaum.

Callanan, M. A., \& Oakes, L. A. (1992). Preschoolers' questions and parents' explanations: Causal thinking in everyday activity. Cognitive Development, 7, 213-233.

Chapa, J., \& Valencia, R. R. (1993). Latino population growth, demographic characteristics, and educational stagnation: An examination of recent trends. Hispanic Journal of Behavioral Sciences, 15, 165-187.

Crowley, K., \& Galco, J. (2001). Family conversations and the emergence of scientific literacy. In K. Crowley, C. Schunn \& T. Okada. (Eds.), Designing for Science: Implications from everyday, classroom, and professional science (pp.393-413). Mahwah, NJ: Lawrence Erlbaum Associates.

Eisenberg. A. R. (2002). Maternal teaching within families of Mexican descent: Influences of task and socioeconomic status. Hispanic Journal of Behavioral Sciences, 24, 2, 206-224.

Esterly, J. B. (2001). 'Its size is really wood': The development of buoyancy and material kind understanding in children between three and seven years of age. Unpublished doctoral dissertation, University of California, Berkeley. 
Goodnow, J. J. (1990). The socialization of cognition: What's involved? In J. W. Stigler, R. A. Shweder, \& G. H. Herdt (Eds.), Cultural psychology: Essays on comparative human development. (pp. 259-286). New York: Cambridge University Press.

Laosa, L. M. (1978). Maternal teaching strategies in Chicano families of varied educational and socioeconomic levels. Child Development, 49, 1129-1135.

Laosa, L. M. (1980). Maternal teaching strategies in Chicano and Anglo-American families: The influence of culture and education on maternal behavior. Child Development, 51, 759-765.

Moreno, R. (1991). Maternal teaching of preschool children in minority and low-status families: A critical review. Early Childhood Research Quarterly, 6, 395-410.

Moreno, R. (1996, April) Instruction across time: The case of Mexican American mothers with an everyday task. Presented at the Annual Meeting of the American Educational Research Association. New York.

National Science Foundation. (1999). Inquiry: thoughts, views and strategies for the K-5 classroom. In Foundations series (vol. 2). Arlington, VA: NSF

Renshaw, P. D. (1992). Reflecting on the experimental context: Parents' interpretations of the education motive during teaching episodes. In L. T. Winegar, \& Valsiner, Jaan (Ed.), Children's development within social context (Vol. 2, pp. 53-74). Hillsdale, NJ: Lawrence Erlbaum Associates.

Rogoff, B. (2003). The cultural nature of human development. London: Oxford University Press. Rogoff, B., Mistry, J., Goncu, A., \& Mosier, C. (1993). Guided participation in cultural activity by toddlers and caregivers. Monographs of the Society for Research in Child Development, 58 (Serial No. 236). 
Rogoff, B. \& Toma, C. (1997) Shared thinking: Community and institutional variations. Discourse Processes, 23,471-497.

Rosebery, A., \& Warren, B (1999). Children's Ways with Words in Science and Mathematics: A Conversation across Disciplines, www.crede.org.

Tenenbaum, H., R., \& Callanan, M. A. (2006). Science talk in Mexican-descent families residing in the US. Manuscript under review.

Tenenbaum, H. R., Callanan, M. A., Alba-Speyer, C., \& Sandoval, L. (2002). The role of educational background, activity, and past experiences in Mexican-descent families' science conversations. Hispanic Journal of Behavioral Sciences, 24, 225-248.

Tenenbaum, H. R., \& Leaper, C. (2003). Parent-child conversations about science: Socialization of gender inequities. Developmental Psychology, 39, 34-47.

Williamson, P.A., \& Silvern, S.B. (1986). Parental teaching styles in an open-ended teachinglearning environment. Early Childhood Research Quarterly, 1(4), 407-415. 
Conversations about Science 30

\section{Footnotes}

1. Some researchers, as well as census reports, use the word Hispanic or Latino to include any Spanish-speaking immigrant groups. That term will be used when describing other research if we are unable to say anything more specific about their samples. In this paper, we prefer the more specific term when referring to our sample - Mexican-descent.

2. Though all family members were invited to participate in the sink-or-float task, the parent that was typically present was the mother and only a very few fathers were present. This led us to focus on the mothers. There were not enough fathers to enable us make comparison between the interactions of mothers versus fathers.

3. In one family all segments were coded as Other, therefore we removed the family from the analyses.

4. Two families did not have distinct prediction and testing tasks as they structured the overall task differently by testing the objects as they predicted each object. These families were only included in analyses on the overall task. 
Table 1

Examples of Coded Utterances

Directive Example

Mother: Don't put it in the water. Whatever you think is gonna stay up in the water, put it right here. What's gonna go down in the water, what's not gonna stay up? The heavy things or the light things?

Child: What is light?

Mother: Light is this (picks up whiffle ball) and heavy is this (picks up marblefilled bottle). Heavy usually go down...

Child: This one was up (picks up whiffle ball)?

Mother: Yeah, put it there.

Collaborative Example

Mother: (stands marble-filled bottle in tub). Look, it's going to sink.

Child: Look. Let's see, give me this one (large water bottle and it floats)...

Mother: It sunk!

Child: $\quad$ Let's see this one...(takes small water bottle from $\mathrm{C} 2$ and it floats). No way!

Mother: (laughs) Look, I thought that it would go [down]. Why do you think it didn't sink?

Child: Well, because they're heavy.

Mother: Yeah, put it there.

Child: $\quad$ Look (pointing to castanets). Put the other ones in. Not that one (yo-yo).

Mother: Doesn't this one float?

Child: Look at this one (puts object in water). This one will.

Instructional Guidance Example

Child: $\quad$ Yeah, this is not floating cuz it's solid <crayon water $>$.

Mother: It's solid?

Child: Yeah, but not these two cause they're so little.

Mother: They look like little? Is that why they're floating?

Child: Yeah.

Mother: And look ... there's plastic and look it, this is wood too <holds up rabbit>. Remember we said wood floats? Put it in there. See, that's wood. This is plastic. And plastic floats.

Child: How about this? <holds up whiffle ball>

Mother: Ok, now we know that plastic floats.

Child: How about this one <holds up whiffle ball>

Mother: Ok, you said all of these are gonna, oh, look at that, it's sinking. Why do you think it's sinking?

Child: No, it's not. Watch. 
Conversations about Science 32

Table 2

Mean Number of Explanations of each Content Type by Parent Schooling

\begin{tabular}{|l|l|l|l|l|}
\hline Parents' Schooling & Density (SD) & Density Relevant (SD) & Other Property (SD) & No Information (SD) \\
\hline Higher & $.15(.49)$ & $11.75(8.78)$ & $1.00(2.10)$ & $.00(.00)$ \\
\hline Basic & $.00(.00)$ & $9.90(9.42)$ & $.45(.68)$ & $.15(.37)$ \\
\hline All & $.08(.35)$ & $10.83(9.04)$ & $.73(1.57)$ & $.08(.27)$ \\
\hline
\end{tabular}

Results reported here reflect the total explanations provided by mothers across the prediction and testing phases of the buoyancy activity. 
Conversations about Science 33

2

3

4

5

6

7

8

9

10 11 12
13 13
14 15 16 17 18 19 20 21 22 23 24 25 26 27 28 29 30 31 32 33 34 35 36 37 38 39 40 41 42 43 44 45 46 47 48 49 50 51 52 53 54 55 56 57 58 59 60

Table 3

Mean Percentages of Interaction Styles Used in Home Task by Parents' Schooling

\begin{tabular}{|c|c|c|c|c|c|}
\hline & & Directive $(S D)$ & Collaborative $(S D)$ & Instructional Guid. (SD) & Other $(S D)$ \\
\hline \multirow[t]{2}{*}{ Prediction } & Basic & $69.65(33.61)$ & $4.47(8.96)$ & $3.86(9.51)$ & $22.02(35.00)$ \\
\hline & Higher & $78.21(31.92)$ & $7.74(21.47)$ & $12.30(26.71)$ & $1.75(7.65)$ \\
\hline \multirow[t]{2}{*}{ Testing } & Basic & $47.41(35.51)$ & $16.57(28.96)$ & $6.18(15.43)$ & $29.83(39.20)$ \\
\hline & Higher & $65.91(38.96)$ & $15.66(29.08)$ & $12.29(22.72)$ & $6.14(14.92)$ \\
\hline \multirow[t]{2}{*}{ Overall } & Basic & $58.22(27.91)$ & $11.97(19.61)$ & $6.07(11.58)$ & $23.73(29.71)$ \\
\hline & Higher & $70.38(32.50)$ & $11.32(20.26)$ & $13.88(22.48)$ & $4.42(9.91)$ \\
\hline
\end{tabular}


Conversations about Science 34

Table 4

Mean Percentages of Interaction Styles at the Museum by Parents' Schooling

Directive (\%) Collaborative (\%) Instructional Guid. (\%) Child Run (\%) Task Orient (\%) Other (\%)

$\begin{array}{lllllll}\text { Basic } & 29.52(28.37) & 21.98(27.67) & 1.16(3.19) & 30.47(30.51) & 1.17(2.92) & 15.69(19.01)\end{array}$

Higher $47.36(28.13) \quad 15.12(17.62) \quad 0.50(1.03) \quad 19.02(23.48) \quad 6.80(9.22) \quad 11.55(13.32)$


2

3

4

5

6

7

8

9

10

11

12

13

14

15

16

17

18

19

20

21

22

23

24

25

26

27

28

29

30

31

32

33

34

35

36

37

38

39

40

41

42

43

44

45

46

47

48

49

50

51

52

53

54

55

56

57

58

59

60
Figure Caption

Figure 1. Mean Percentage of Collaborative Interactions in Prediction and Testing Phases of the Home Task and at Museum by Schooling Level and Gender. 
Conversations about Science 36

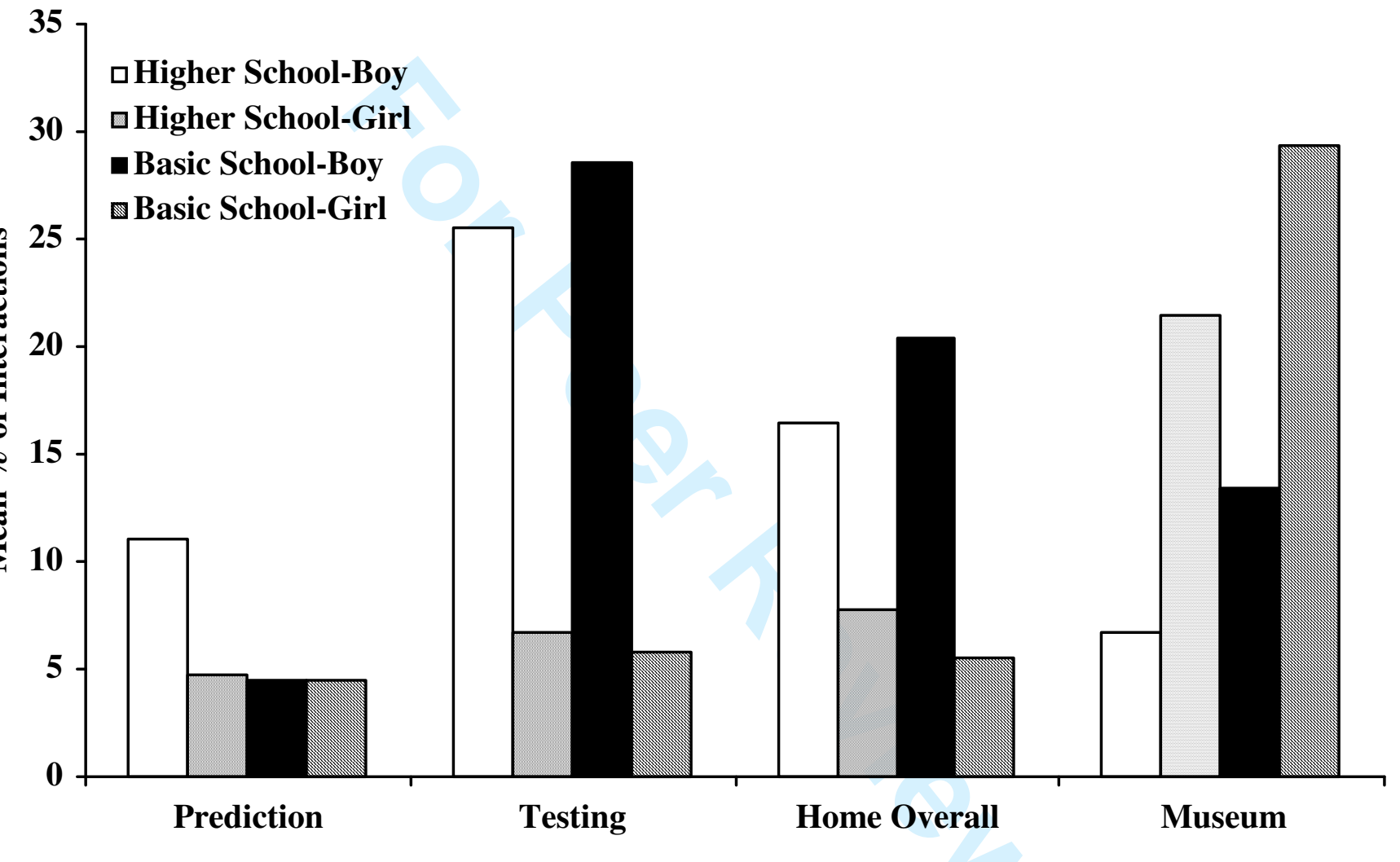


Acknowledgements

This research was supported by an NIH predoctoral grant awarded to the first author, by an NIH postdoctoral grant to the second author, and by grants to the third author from both the Center for Research on Education, Diversity \& Excellence (CREDE) funded by the Department of Education and the Center for Informal Learning and Schools (CILS) funded by the National Science Foundation. We are grateful to Rocio Navarro for substantial assistance with devising the coding scheme, translating, and coding the data, and to Consuelo Alba-Speyer, Harriet Tenenbaum and Leticia Sandoval for recruiting families and collecting data. We also thank Barbara Rogoff for helpful comments on an earlier draft. Finally, thanks are due to the children and parents who participated in the studies. 